\title{
A Case Study: The Urban Residents' Choice for Electric Vehicles Warning Sounds
}

\author{
Mia Suhanek*, Ivan Djurek, Antonio Petosic \\ Department of Electroacoustics, Faculty of Electrical Engineering and Computing, University of Zagreb, Zagreb, Croatia
}

\section{Email address:}

mia.suhanek@fer.hr (M. Suhanek)

*Corresponding author

\section{To cite this article:}

Mia Suhanek, Ivan Djurek, Antonio Petosic. A Case Study: The Urban Residents' Choice for Electric Vehicles Warning Sounds. American Journal of Environmental Science and Engineering. Special Issue: Smart Cities - Innovative Approaches. Vol. 3, No. 3, 2019 , pp. 47-51. doi: 10.11648/j.ajese.20190303.11

Received: September 18, 2019; Accepted: October 15, 2019; Published: October 23, 2019

\begin{abstract}
Nowadays, people are exposed to noise on a daily basis. Therefore, in an overvibrant urban environments electrical vehicles operating at low speed are too quiet to be detected by pedestrians (especially vulnerable group are visually impaired people) and urban residents in general. Thus, electric vehicle warning sounds are sounds created to alert and warn pedestrians to the presence of electrical vehicles (e.g. hybrid electric vehicles, plug-in hybrid electric vehicles and all-electric vehicles) moving at low speeds. The goal of this paper is to determine through a case study what the pedestrians would desire and prefer the electrical vehicle warning audio signals to sound like. The case study involved 201 participants who had the task to fulfil a specially designed questionnaire for this purpose. Regarding the questionnaire, the participants were not prepared in any way for the testing they were just advised to keep in mind that the warning sound they select for the "role" of a pedestrian should not be irritable at the same time for the "role" of a driver. The results obtained from the questionnaire were analyzed and discussed in the paper. When speaking about the concept of smart cities and the legislation around the whole world today this is certainly a hot topic where the opinion of pedestrians and future drivers should not be overlooked.
\end{abstract}

Keywords: Electric Vehicle, Warning Sounds, Audio Signal, Pedestrian Safety, Smart Cities

\section{Introduction}

People are exposed to different sound environments on a daily basis. Noise pollution is often overlooked when compared to other different environmental pollutions (e.g. air pollution, water pollution, soil pollution etc.). Long exposure to noise pollution can be displayed as a bad mood, fatigue, insomnia, headache and loss of concentration, which causes reduced work ability and ultimately permanent hearing impairment [1-3]. Concerning the noise pollution, electrical vehicles represent the future especially when compared to vehicles with internal combustion engine [4] (see Figure 1 [5]).

However, at low speeds electrical vehicles produce very little noise, or to say it even harshly, in these urban environments they are practically inaudible. For example, the noise level difference between an electrical vehicle and one with an internal combustion engine (ICE) can be as large as 6 $\mathrm{dB}(\mathrm{A})$ at $10 \mathrm{~km} / \mathrm{h}$ [6]. Unfortunately, much later, when developing higher speeds both types of cars become equally loud mainly due to tires noise.

In urban environments, for pedestrians (especially the visually impaired ones) this significantly lower sound level makes it quite difficult to detect electrical vehicles [6].

Since 2009 the Japanese government, the U.S. Congress and the European Commission are studying legislation in order to determine a minimum level of sound for plug-in electric and hybrid electric vehicles when operating in electric mode, so that visually impaired people, other pedestrians and cyclists can hear them coming and detect from which direction they are approaching. Several tests and research have shown that vehicles operating in electric mode can be particularly hard to hear below $32 \mathrm{~km} / \mathrm{h}$ [7-10]. 


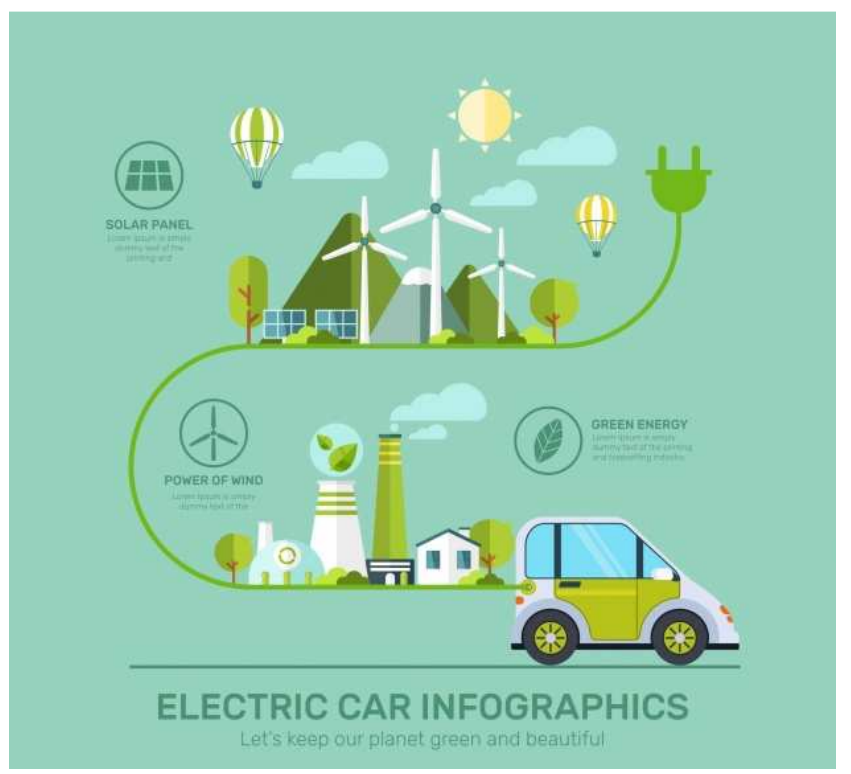

Figure 1. The future - electrical vehicles [5].

In 2011 the European Commission composed a guideline for Acoustic Vehicle Alerting Systems (AVAS). The goal of the guideline was to present recommendations to manufacturers for a system to be installed in vehicles to provide an audible signal to pedestrians and vulnerable road users. The guidelines are proposed for hybrid electric and pure electric highway-capable vehicles. The guideline recommends that the $A V A S$ should automatically generate a continuous sound in the minimum range of vehicle speeds from start-up to approximately $20 \mathrm{~km} / \mathrm{h}$ and during reversedriving, if applicable for that vehicle category, and in addition lists the types of sounds that are not suitable. It also gives a choice that the $A V A S$ may have a pause switch to stop its operation temporarily [11]. On February $6^{\text {th }} 2013$, the European Parliament decided that the draft legislation states a number of tests, standards and measures that must first be developed for an Acoustic Vehicle Alerting Systems (AVAS) to be mandatory in the future. The approved amendment determines that "the sound to be generated by the AVAS should be a continuous sound that provides information to the pedestrians and vulnerable road users of a vehicle in operation. The sound should be easily indicative of vehicle behaviour and should sound similar to the sound of a vehicle of the same category equipped with an internal combustion engine" [12]. In April 2014 the European Parliament approved the legislation (Regulation (EU) No 540/2014) that requires the Acoustic Vehicle Alerting Systems, which is obligatory for all new electric and hybrid electric vehicles. The new instruction proposes a transitional period of 5 years after publication of the final approval of the April 2014 proposal to comply with the regulation $[13,14]$.

Bearing in mind all of the aforementioned, the motivation for this research was to find out the pedestrians "wishes" and expectations regarding the warning sounds which will be added to electrical vehicles in order to preserve and improve traffic safety. The target study group are mainly younger people who just obtained their driving licence or people who are preparing for their driving test since electrical vehicles are the future and it can be expected from that type of group to give significant results.

\section{The Methodology in the Study}

This case study will address the issue of electric cars in everyday traffic. The research will focus on assigning a desirable (both for pedestrians and drivers) and, at the same time, detectable warning sound to an electrical vehicle in the daily traffic. In addition, the participants were given instruction to especially keep in mind slow moving of the vehicle and breaking of the vehicle.

Age Gender __
1. Have you obtained your driving licence?
a) Yes
b) No
2. Are you an "active" driver (do you drive almost every
day)?
a) Yes
b) No
3. Do you find it logical and desirable that electrical vehicles
should be assigned a warning sound which imitates a car with
internal combustion engine?
a) Yes
b) No
irritating the driver.
4. (If you answered the previous question with No) Which of
the following sounds do you consider suitable and detectable
as a warning sound for electrical vehicles?
a) Modulated noise
b) Beeping (the sound that most cars make when
e) your don't have your seatbelt on)

Figure 2. The design of the questionnaire.

The target group involved 201 participants with a median age of 19 years old. $91 \%$ of participates are male and $9 \%$ female. 
For the purpose of this research a specially designed questionnaire was designed. The participants had to fulfil their age and gender otherwise the questionnaire was anonymous. The participants were not prepared in any way for the testing they were just advised to keep in mind that the warning sound they select for the "role" of a pedestrian should not be irritable at the same time for the "role" of a driver [15]. The questionnaire consists of four questions shown in Figure 2.

\section{The Results}

As previously stated, the study involved 201 participants (i.e. median age of 19 years old, $91 \%$ of participates are male and $9 \%$ female). $40 \%$ of the case study participants have already obtained their driving licence (i.e. 87 of them) while $60 \%$ were in the process of obtaining their driving licence (please see Figure 3.).

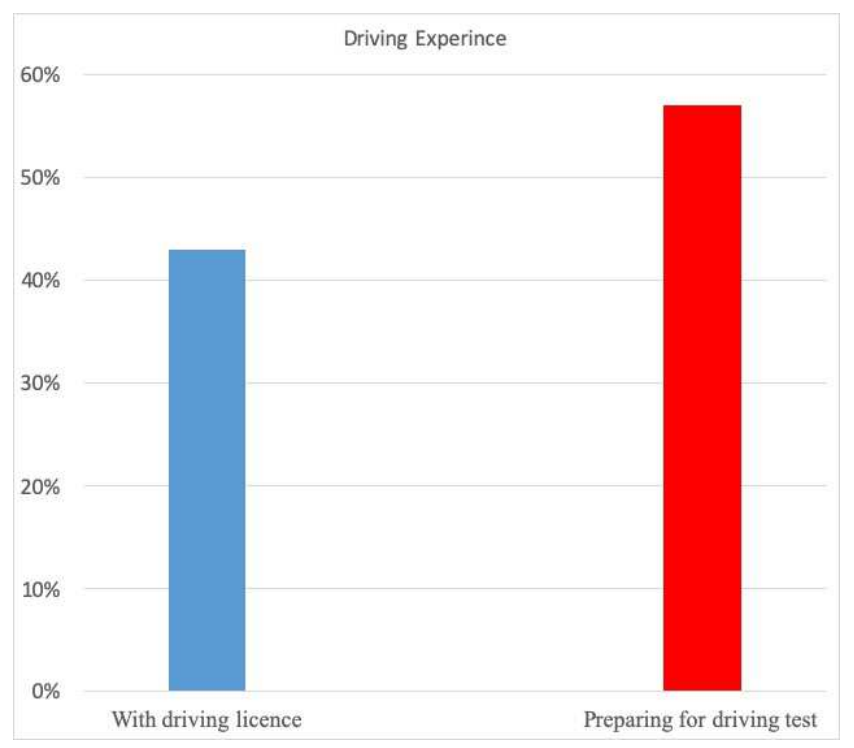

Figure 3. Driving experience distribution of the survey participants.

Out of 87 of them with driving licence $45 \%$ considers themselves as everyday drivers which is shown in Figure 4.

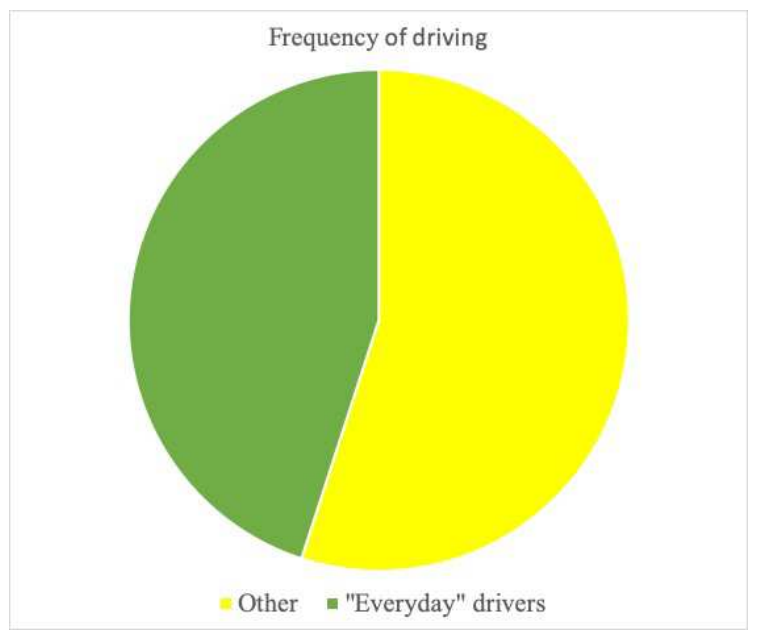

Figure 4. Frequency of driving for the participants who have attained their driving licence.
A) The preferred warning sounds for the group with driving licence

The majority of the group "drivers" has decided that the most suitable warning sound for electrical vehicles would be the sound of a car with internal combustion engine (i.e. $45 \%$ ). $27 \%$ of participants think that a sound of an electrical motor would be a better solution, while $21 \%$ of them would add a sound of modulated noise. Only $7 \%$ of young drivers would like that their cars emit a musical signal while no one would like that their electrical vehicle beeps. The results for the "drivers" are shown in Figure 5.

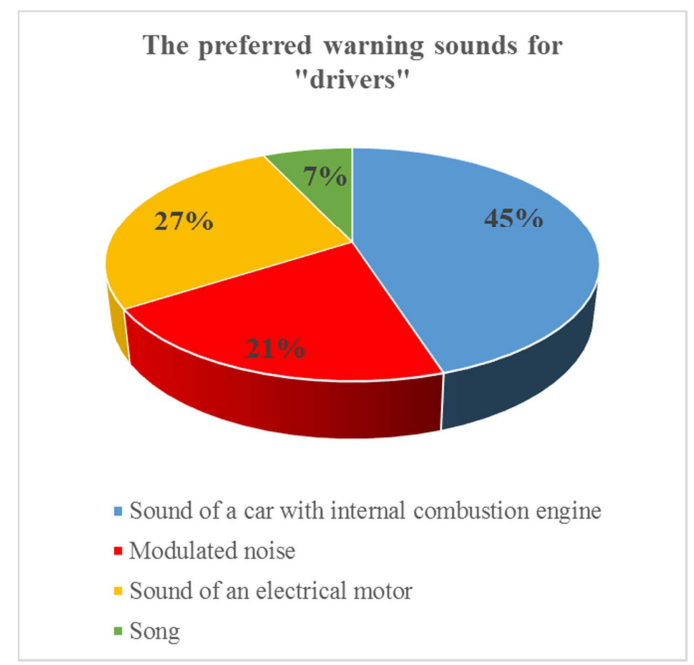

Figure 5. The preferred warning sounds for the group with a driving licence.

B) The preferred warning sounds for the group in the process of obtaining their driving licence

Within the group of "non-drivers" (i.e. $37 \%$ of them) thinks that the most appropriate warning sound for an electrical vehicle would be the sound of a car with internal combustion engine. $34 \%$ of them would prefer the sound of electrical motor while $18 \%$ would use modulated noise. Once again nobody would like beeping as a warning sound. $11 \%$ of "non-drivers" would like a musical signal as a warning sound for their electrical vehicle. The results for this group are shown in Figure 6.

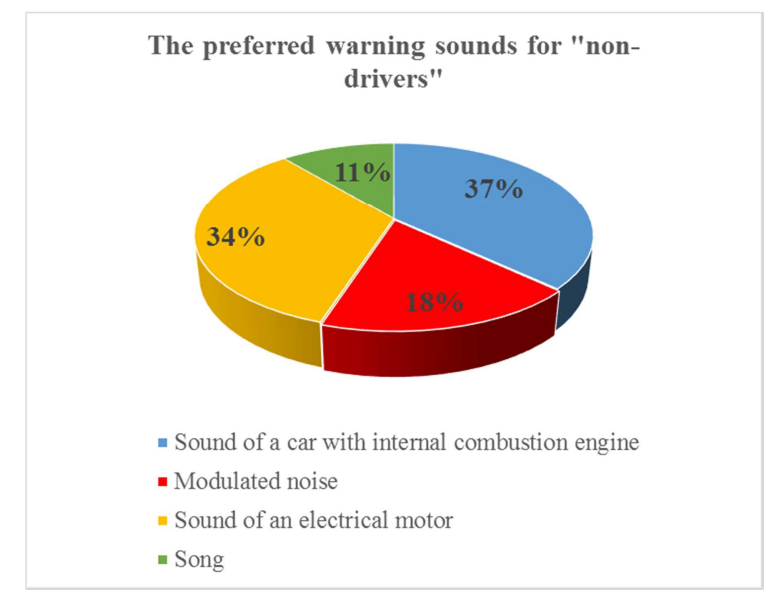

Figure 6. The preferred warning sounds for the group with no driving licence yet. 


\section{The Discussion}

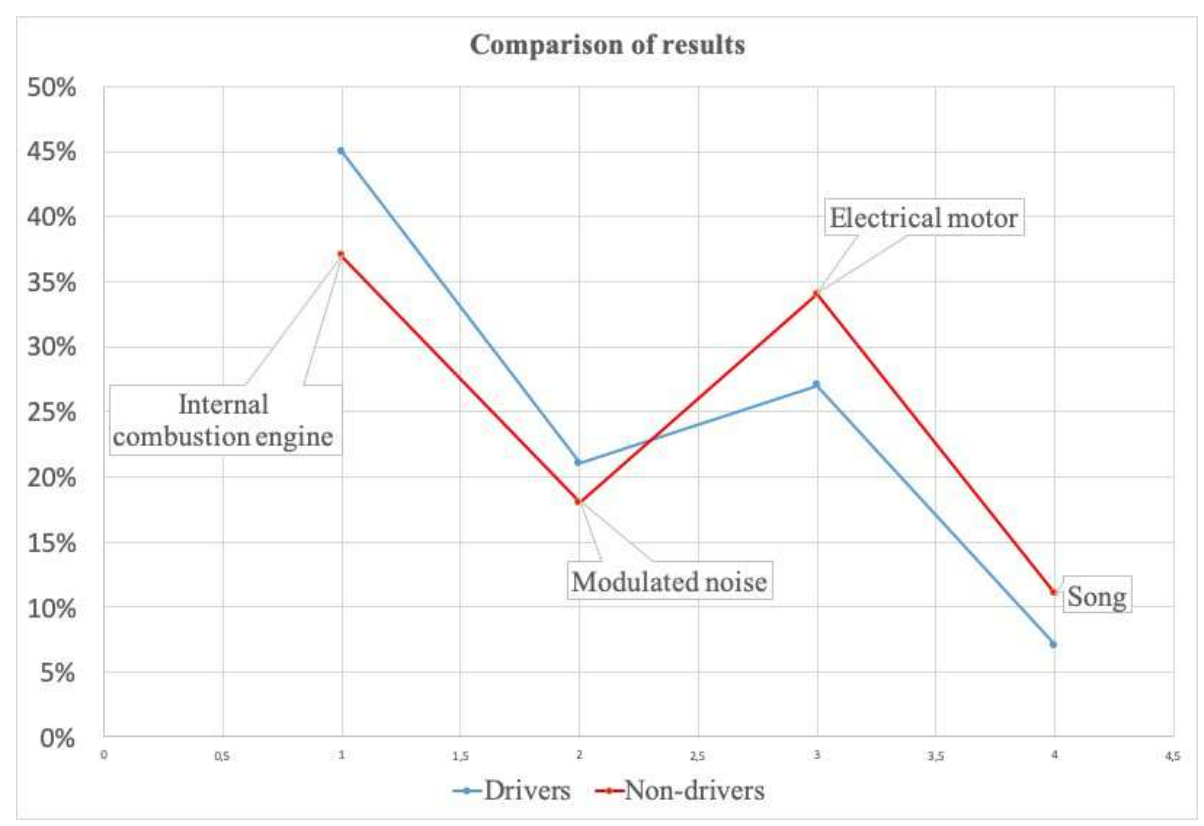

Figure 7. Comparison of results for the "drivers" and "non-drivers" group.

If we compare the results of drivers and non-drivers, they are quite similar especially in the cases of modulated noise and songs as examples of warning sounds for electrical vehicles (shown in Figure 7). In addition, we can conclude that the minority of participants would desire these two examples as warning sounds for their electrical vehicle. The majority of drivers would prefer that their electrical vehicle sounds like an internal combustion engine car. During the study we got the answer from many participants, in particular the drivers, to quote: "We want that a car sounds like a car". The non-drivers are more open to the solution that an electrical vehicle has a different sound than a "regular" car. They are more opened to a solution of adding a sound of an electrical motor to the electrical vehicle as a warning sound. This would distinguish the electrical cars from cars with internal combustion engine in everyday traffic. An important question concerning the overall quality of life is which one of these two sounds would increase more the noise levels in urban environments. In addition, there is a question of the drivers' annoyance. It is quite logical that the majority of people (both drivers and pedestrians) want that "a car sounds like a car" simply because they are used to it.

\section{Conclusion}

In this paper we have presented the results of a short study which aim was to discover the pedestrians' preferences concerning the warning sounds which would be added to electrical vehicles in order to preserve and improve traffic safety. At low speed electrical vehicles produce very little noise (i.e. they are practically inaudible in urban environments) and therefore pose a danger for pedestrians, especially for visually impaired ones.
In this research the target study group were mainly younger people who just attained their driving licence or people who are preparing for their driving test. The group is not selected randomly. Since it can be expected that electrical vehicles are the "future" then it can also be expected from younger people that they will be the ones driving them and thus, from a scientific point of view that type of group would give significant research results.

In order to gain their opinion, we have designed a questionnaire for this study. It was found that regardless of the fact if the participant has a driving licence or is in the process of obtaining one two warning sounds have imposed i.e. the sound of an internal combustion engine car and a sound of an electrical motor. The explanation that we got from the participants for the first choice (an internal combustion engine car) can actually be attributed to a human habit (people are used to a "sound of car"). The explanation for the second choice (i.e. electrical motor) was that since it is an electrical car it would be quite logical that it sounds more like an electrical motor rather than a "regular" car and that there should exist a distinction between these two types of vehicles.

Regardless of the final choice there are still a few questions or to say problems to be tackle through real case scenario experiments and laboratory listening which we plan to do in our future work. This future research should answer the question how loud the warning sound should be in order to be notice in urban environments. Another concern is how much will be adding the warning sounds contribute to the overall traffic noise pollution and bearing in mind all of the aforementioned, which sound is a better choice i.e. a sound of an internal combustion engine car or a sound of an electrical motor. Finally, the results of this case study can 
serve as a certain guideline for all manufacturers in terms of their final choice for a warning sound for their brand of electrical vehicles.

\section{References}

[1] H. Ising, B. Kruppa; "Health effects caused by noise: Evidence in the literature from the past 25 years", Journal Noise and Health, 2004, 6 (22), p. 5-13.

[2] M. Basner, W. Babisch, A. Davis et al; "Auditory and nonauditory effects of noise on health", Lancet PMC, 2014; 383 (9925); p. 1325-1332.

[3] European Commission. Noise impacts on health. Science for Environment Policy; 2015.

[4] L. Maffei, M. Masullo, Electric "Vehicles and Urban Noise Control Policies", Archives of Acoustics, 2014, p. 333-341.

[5] www.pixabay.com

[6] E. Parizet, P. Pondrom, K. Janssens, "Additional Efficient warning sounds for electric and hybrid vehicles", Applied Acoustics 86, 2014, p. 50-58.

[7] TMC to Sell Approaching Vehicle Audible System for 'Prius'". Toyota Motor Company News Release. 2010-08-24. Retrieved 2010-08-25.

[8] J. Motavalli (2010-06-17), "Blind Advocates 'Disappointed' in Nissan E. V. Sounds for Pedestrians". The New York Times.
Retrieved 2010-06-19. The article includes a sample of the two sounds.

[9] "Electric cars and noise: The sound of silence". The Economist. 2009-05-07. Retrieved 2009-05-08.

[10] Mike King (2010-06-02). "Hybrid cars not noisy enough, group says". The Gazette (Montreal). Retrieved 2010-07-0.

[11] Working Party on Noise (GRB) Quiet Road Transport Vehicle Working Group (2011-03-11). "Annex VIII - Proposal for guidelines on measures ensuring the audibility of hybrid and electric vehicles" (PDF). United Nations Economic Commission for Europe. Retrieved 2013-03-17.

[12] European Parliament (2013-02-06). "European Parliament legislative resolution of 6 February 2013 on the proposal for a regulation of the European Parliament and of the Council on the sound level of motor vehicles (COM(2011)0856-C70487/2011-2011/0409(COD))". European Parliament. Retrieved 2013-03-17. See Amendments 16, 20, 58 and 59.

[13] Ray Massey (2014-04-02). "Silent but deadly: EU rules all electric cars must make artificial engine noise". Daily Mail. Retrieved 2014-04-03.

[14] European Commission Press Release (2014-04-02), "Commission welcomes Parliament vote on decreasing vehicle noise", European Commission. Retrieved 2014-04-03.

[15] E. Parizet,, R. Robart, J. C. Chamard, J. Schlittenlacher, P. Pondrom, W. Ellermeier et al. (2013), "Detectability and annoyance of warning sounds for electric vehicles" Proceedings of Meetings on Acoustics, 19, 2013. 